Article

\title{
Energy and Microclimate Simulation in a Heritage Building: Further Studies on the Malatestiana Library
}

\author{
Lamberto Tronchin ${ }^{1, *,+}$ (D) and Kristian Fabbri ${ }^{2,+}$ \\ 1 Department of Industrial Engineering, University of Bologna, Viale del Risorgimento 2, \\ 40129 Bologna, Italy \\ 2 Department of Architecture, University of Bologna, Viale Europa 596, 47521 Cesena, Italy; \\ kristian.fabbri@unibo.it \\ * Correspondence: lamberto.tronchin@unibo.it; Tel.: +39-051-209-0542; Fax: +39-051-209-3296 \\ + These authors contributed equally to this work.
}

Received: 6 September 2017; Accepted: 6 October 2017; Published: 16 October 2017

\begin{abstract}
Historical and heritage (especially UNESCO) buildings need a specific, peculiar approach regarding energy performance, energy behavior, and indoor microclimate. Comparing a new building with a historical (UNESCO) building, it is evident that the degrees of freedom for implementing energy efficiency in historical buildings are strongly limited. Several constraints about the materials, the geometry, and the structures do not allow a comprehensive enhancement of energy performance or microclimate parameters. In this paper, we describe an energy building performance criterion adopted in order to find out the energy behavior in the Malatestiana Library. The challenge consists of optimizing energy efficiency and microclimate as well as a full preservation of ancient manuscripts. The study adopts Google Sketchup software to model three-dimensional (3D) buildings, and IESVE software to simulate an indoor microclimate. Software building models allow for the evaluation of different types of natural ventilation and section forms, e.g., original, without attic, and without ground floor. The results of the software modeling allow for a comparison of several building use modality effects and the effect of the presence of an attic and ground floor on indoor microclimate parameters in order to conserve and preserve ancient manuscripts.
\end{abstract}

Keywords: building simulation; heritage building; indoor microclimate; Malatestiana Library

\section{Introduction: Energy Building Simulation in a Heritage Site}

Historical buildings, especially heritage buildings, have specific characteristics regarding building energy performance behavior and modeling. On one hand, these building are generally excluded from minimum energy requirement obligations and energy performance certification (e.g., Directive 2010/31/UE of the European Parliament and of the Council of 19 May 2010 on the energy performance of buildings (recast) excludes heritage buildings). On the other, heritage buildings have several kinds of use: museums, the building as a museum itself, archives, offices, dwellings, etc. Moreover, the use of these buildings requires the maintenance of a comfortable indoor microclimate for its users, guaranteed by Heating, Ventilation, and/or Air-Conditioning (HVAC) systems.

The main questions concern:

(a) how to insert HVAC systems in historic buildings;

(b) how to reduce energy consumption and energy costs, which have an economical incidence on heritage bills, as described by in F. Ascione [1];

(c) the study of building behavior in order to:

(i) control the indoor microclimate level to guarantee building and artifact conservation; 
(ii) guarantee an indoor microclimate level to satisfy user comfort;

(iii) improve HVAC system management in order to satisfy the above two points.

Historical buildings have another peculiarity: they were built before the invention of modern technical HVAC systems and were previously heated by braziers, a fireplace, or stove. Moreover, it would be interesting to study the architectural solutions that allowed the building to be used in the past. For this reason, it is worthy of interest to analyze the effects of different architectural solutions on the energy behavior, indoor microclimate, and preservation of the materials hosted in these important structures.

Building Performance Simulation (BPS) by dynamic software, e.g., EnergyPlus, Trynsis, and ESPr, allow for the calculation and study of an indoor microclimate and how it is influenced by boundary conditions: outdoor climate, user and human behavior, HVAC systems, heating load, etc. A comparison between indoor microclimate in an actual building configuration and a historic (in the past) configuration shows any deficiency that depends on historical buildings and that depends on "modern use", e.g., with plant or new modern standards. In order to make the above comparison, the building must be a "patient zero"; in other words, a heritage building in which nothing has changed since the time it was built, and, if possible, has conserved its inside use and artifacts.

This paper describes an indoor microclimate simulation of a "zero patient" building: the Malatestiana Library located in Cesena, in central northern Italy. The goal of this study is to find, through Building Energy Performance (BEP) Simulation, how indoor microclimate air perfectly conserves wooden desks and parchments without any HVAC system.

The first problem of the BEP simulation of heritage buildings is geometrical and thermo-physics modeling, as well as HVAC modeling if the building has a HVAC system. Scientific literature reports some research on the subject, but with a different kind of approach. The focus of the Balocco [2] study concerns a problem of HVAC systems' effect in heritage buildings, or, in other words, the suitable air-conditioning plant design in the case of heritage buildings, and their influence on thermo-physics behavior. The research is on the Hall of the Five Hundred di Palazzo Vecchio in Florence, in which the authors compare several HVAC configurations and Computer Fluid Dynamics (CFD) software results.

Also, the studies of D'Agostino [3] and Corgnati [4] deal with the CFD simulation of heritage buildings, but in this case, buildings without HVAC systems. Other research addresses particular problems of heritage buildings, such as air humidity effect or humidity transfer through walls, as described in D'Agostino's work [5,6] on heritage church buildings without HVAC systems, and Bernardi's research [7] that describes the indoor microclimate in another church. The goals of these studies are the microclimate's effect on walls, or inside walls, with "mass transfer phenomenon", and are not about indoor air microclimate. An article by Samek [8] studies the indoor air microclimate of a church building, monitoring the effect of overhead electric radiant heaters. Further possibilities could be analyzing the building by exergy methods or multiscale analysis as in Fabbri and Tronchin's works $[9,10]$.

The study of the indoor microclimate in heritage buildings as regards buildings with HVAC systems, and the effect of these on original buildings, is described in Camuffo [11] for energy retrofit [12,13], and, in particular, museum buildings [14,15].

From a BEP simulation point of view, historic buildings are the same as all buildings; it is possible to know the geometry, while it is difficult to know the material thermo-physics parameter. In any case, it is possible to accurately simulate an indoor air microclimate; furthermore, it is possible to evaluate the range of variations of two parameters that have a main influence on artifacts: air temperature and relative humidity, which in turn are influenced by indoor air ventilation (air velocity and turbulence).

\section{Aims of the Research}

The aim of the research here presented consists of verifying the use of numerical models and existing tools (i.e., SkecthUp and IESVE) in the modeling of Heritage Buildings. More precisely, 
the most important task consists in verifying the amount of the influence of architectural configurations (with or without the roof, first floor, etc.) on the indoor microclimate thermal parameters. Although a more detailed evaluation of the thermo-physics parameter could be obtained by means of the validation of the numerical model, a comparison of different architectural scenarios does not require a specific validation, because the research aims to compare the differences and not the absolute values.

\section{The UNESCO Site}

In this research, we will demonstrate the criterion for modeling a historical building with a dynamic model. Our aim is to study the indoor microclimate behavior of the Malatestiana Library in Cesena (Figures 1 and 2).

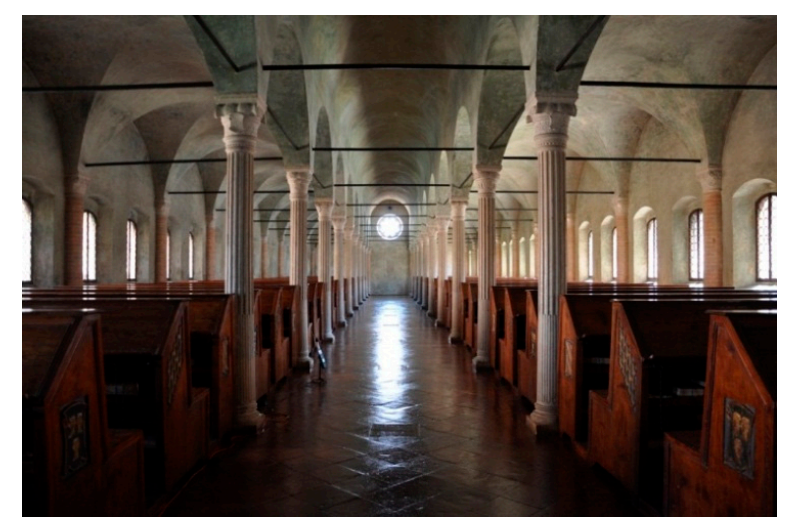

Figure 1. The Malatestiana Library, Cesena: interior view.

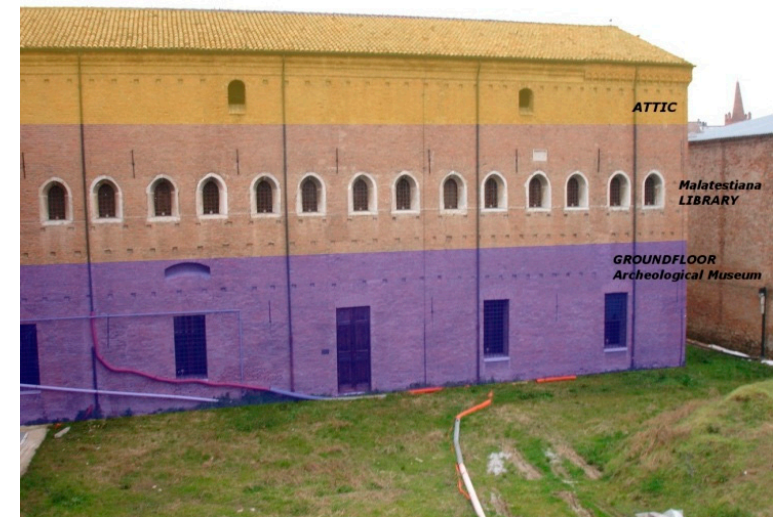

Figure 2. The Malatestiana Library, Cesena_external view.

In the following, Google Sketchup [16] was utilized in order to realize a three-dimensional (3D) virtual model. Also used was the software IESVE [17], which has been applied in several research papers, such as Said [18], which describes a long-term monitoring of the hygrothermal performance of the building envelope of a heritage building in Ottawa, and in the Guidelines of Historical Scotland, where century villa modeling with IESVE is described. In these case studies, the software modeling adopts a dynamic model. The goal of this paper is to know how the building geometry and architectural section of Malatestiana Library influences its indoor microclimate. In this particular case, our aim is to evaluate the roof and "attic influence".

The Malatestiana Library can be modeled as a parallelepiped, about $40 \mathrm{~m} \times 10 \mathrm{~m} \times 4 \mathrm{~m}$ (height), below which there is a space with the same dimensions but $8 \mathrm{~m}$ high, and above a $4 \mathrm{~m}$ high attic and approximately $1.5 \mathrm{~m}$ of roof gutter line (Figure 3). The attic reduces solar radiation and solar gain in the summer period and provides insulation during the winter period. In this paper, we study the effect 
of the attic on the indoor microclimate, and furthermore building modeling and dynamic simulation with BEP software, such as IESVE, and how it can be useful for this kind of research.

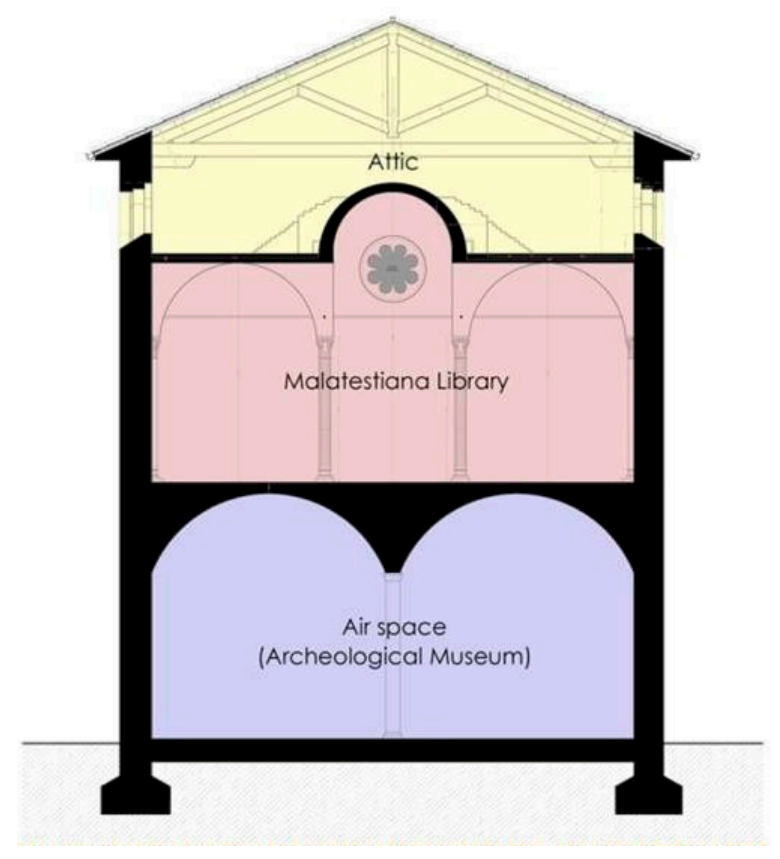

Figure 3. The model of the Malatestiana Library.

\section{Methodology: Introduction}

As reported earlier, the work here presented does not contain a validation of the numerical model, because it is not necessary. The main purpose of the work consists in comparing the role in energy behaviour of different architectural solutions in historical buildings, rather than investigating several different solutions for optimising microclimate and energy efficiency in the Malatestiana Library.

The parameters here considered during the research are those which describe the indoor microclimate and were previously introduced, i.e., the indoor air temperature $\left({ }^{\circ} \mathrm{C}\right)$, which allows us to determine the indoor/outdoor heating exchanges; the relative humidity $(\mathrm{RH})(\%)$, which is strongly influenced by the indoor air temperature; the air velocity $(\mathrm{m} / \mathrm{s})$, which allows us to determine the convective fluxes and movements of fine particulate matter (PM10/PM2.5). Moreover, air temperature and relative humidity are quite important for a proper preservation of ancient manuscripts, such as ancient books.

The numerical simulation does not require special equipment: a normal notebook having an Intel i3 Processor and $1 \mathrm{~Gb}$ of random access memory (RAM), allows one to perform a simulation with Google Sketchup IESVE.

\subsection{Adoption of Sketchup Model}

The first step in studying an indoor microclimate, with and without an attic, is to model the building. We decided to use IESVE software and to construct the 3D model with Google Sketchup (Figure 4).

The studies of Ellis [19] and Attia [20] adopted Google Sketchup to evaluate building performance with Energyplus. The geometric precision of the 3D modeling should be good enough, but in order to study an indoor microclimate it is preferable to develop a "lightweight" file to speed up the interface model, the calculations, and the simulation results. Sketchup has some advantages: a simplified and intuitive design, a parametric system to define a two-dimensional (2D) and 3D architectural form, the adoption of intuitive 3D modeling with extrusion with a push and pull command and 
a Boolean data-type command. Furthermore, it allows users to define geographic coordinates (Geographic Information System, GIS) with latitude and longitude, so as to simulate solar and shade surfaces. Google Sketchup has a plug-in to the BPS IESVE software.

The IESVE software is capable of simulating energy and microclimate behavior when interfaced with the Energyplus "engine". The tasks and commands of IESVE allow users to carry out simulations for: energy building performance, Computer Fluid Dynamics (CFD), heating, ventilation, air-conditioning plants, human comfort, and environmental impact.

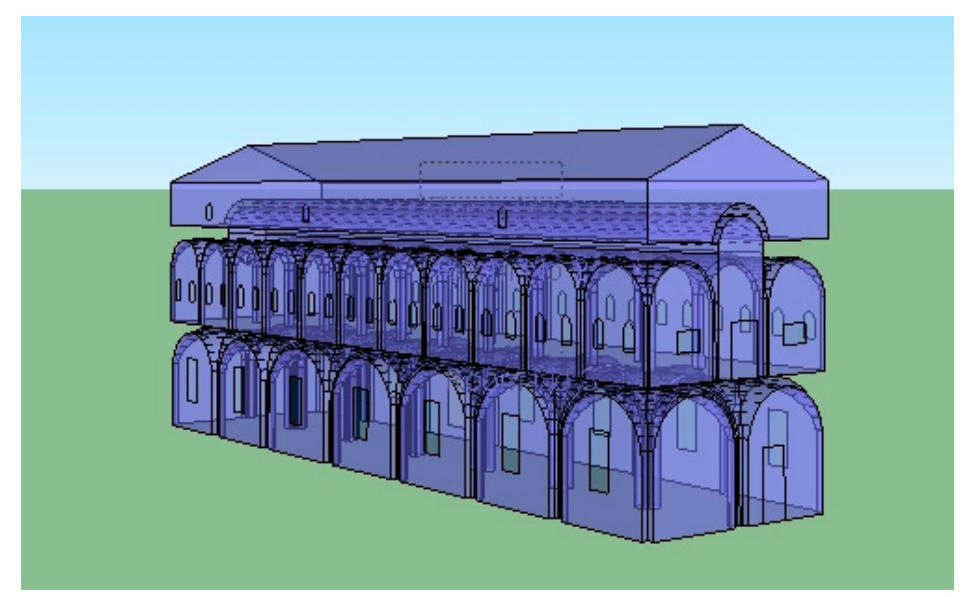

Figure 4. The three-dimensional (3D) Model of the Library.

\subsection{The Modeling}

The 3D model was realized using Google Sketchup. The Malatestiana Library was divided into three zones, from the top:

- An attic, which is not used,

- A library with windows, a cross volt, and a barrel vault,

- A space under the library, which is currently an archaeological museum as shown in Figure 3.

The 3D model is a "wireframe model" of the building's geometry, and all the thermo-physics information of the walls and structure are inserted with IESVE.

Furthermore, IESVE allows users to insert all climate and location data with APlocated selection (selection wizard). The climate data file has two file extensions: the FTW by IESVE and the EPW by Energy plus and the U.S. Department of Energy (DOE) file extensions. We adopt a 10-min step for the climate data, this step is enough in the case of building simulations. The CFD command allows users to model the air flow, air velocity, and temperature distribution. The CFD reveals indoor air behavior in relation to space distribution, building use, and window opening time.

\subsection{The Malatestiana Library}

The object of study is the Malatestiana Library, located in Cesena (center-north Italy), the only medieval library that has not undergone any changes since it was built in 1452 by Novello Malatesta dei Malatesti Prince. The Malatestiana Library of Malatesta Novello is on UNESCO's Memory of the World list (Memoire du Monde' Register) [21,22]. The aim of the UNESCO Memory of the World list, set up in 1992, is to preserve and make a Uniqueness Document for Human History. In 2005, UNESCO identified the Malatestiana Library as a "Unicum library", the first one in Italy and in the World. It includes the same building, same wooden desks, and same manuscripts from 1452 until today. Furthermore, it has been used as a public library until today, not just a museum. For these reasons, we would like to know how this perfect conservation of wooden desks and manuscripts was possible through almost 600 years without any HVAC system. 
The Malatestiana Library was the first Italian civic library. Commissioned by the Lord of Cesena, Novello Malatesta, the works were directed by Matteo Nuti from Fano (probably a pupil of L. B. Alberti), lasted from 1447 to 1452, and were completed with furniture and manuscripts in 1454 . The aula has a basilica shape with three naves, which are divided by ten rows of white, local stone columns. The central nave is higher $(6.30 \mathrm{~m})$ than the aisles $(4.10)$; the span is eleven for each aisle, pole vaulted. The central nave is barrel vaulted and ends with a rose, under which is the gravestone of Novello Malatesta. The fittings are composed of 58 desks; light comes in through 44 windows. The building has three levels, the lower and the upper working exclusively to ensure the best conditions for conserving the books in the middle one. The room in which books (better still, manuscripts) are conserved has:

- a large number of windows (light, exchange of air); and

- the minimum amount of wooden structures (just the windows and the desks, no wooden beams or planks), to avoid fire risks.

The fittings are composed of desks made of larch wood (one of the less inflammable types of wood). Also, from a structural point of view, the building is absolutely singular, with a strong resistance to earthquakes:

- the particular internal structure, with a large two-naves lower level, is barrel vaulted;

- a three-naves middle level, really light in its structures, is superimposed over the two lower level naves;

- a totally free third level has large trusses, the bonds of which are very far from the superior part of the vault;

- tie rods at every level, linking together all the internal and external structures, pillars, columns, and walls.

This library has preserved its structure, fittings, and codices for more than 550 years since its opening. The thickness of the external walls reduces the heating flow through the walls in order to improve thermal inertia. The internal environment is constituted by an area of $40.87 \times 10.47 \mathrm{~m}$ on the map (nearly a surface of $427 \mathrm{~m}^{2}$ ) and a height of $4.10 \mathrm{~m}$ in the lateral vaults and $6.30 \mathrm{~m}$ in the central vault, for a total indoor volume of around $1974 \mathrm{~m}^{3}$. The room has a wooden door of $1.55 \times 2.33 \mathrm{~m}$ with double locks and side openings, each one of $0.855 \times 1.28 \mathrm{~m}$, separated from the inside by a bar which allows air to flow from the inside of the Malatestiana Library to other rooms of a new building, which is used for museums and civic libraries.

The inside environment has no plant system, if we exclude the fire alarm and burglar alarm, to be found on the smaller walls of the Library. The plutea and manuscripts are displayed according to the wishes of Novello Malatesta. On the longer sides, there are 22 windows on each side, measuring $0.66 \times 1.20 \mathrm{~m}\left(0.79 \mathrm{~m}^{2}\right)$, which are without hermetic wooden frames and have simple glass panes. Externally, they are protected by a grill to avoid the entrance of birds and by an electrostatic system to repel pigeons.

The Malatestiana Library environment is enclosed between two air spaces.

(a) Underneath there exists a large vault place, actually used as an archaeological museum. The space is $5.30 \mathrm{~m}$ high; therefore, the level of access to the library is $5.70 \mathrm{~m}$ from the ground, so the indoor environment of the library is not influenced by ground temperature variation and other correlated phenomena (rising humidity, flooding, etc.).

(b) Above there is an attic (Figure 5), a space at present not in use, its maximum height is $2.70 \mathrm{~m}$, and it has an outside ventilated opening (without window or frame) with wooden roofing, a truss covering, secondary beams, small beams, and earthenware tiles.

The attic reduces the solar radiation effect on the library's ceiling, because there is not any continuity in heat transmission, by irradiation, which strikes the outside roofing going towards the 
environment inside the Library. The air-ventilated attic guarantees the convective exchange of air inside the room, in order to avoid all overheating and air stratification phenomenon.

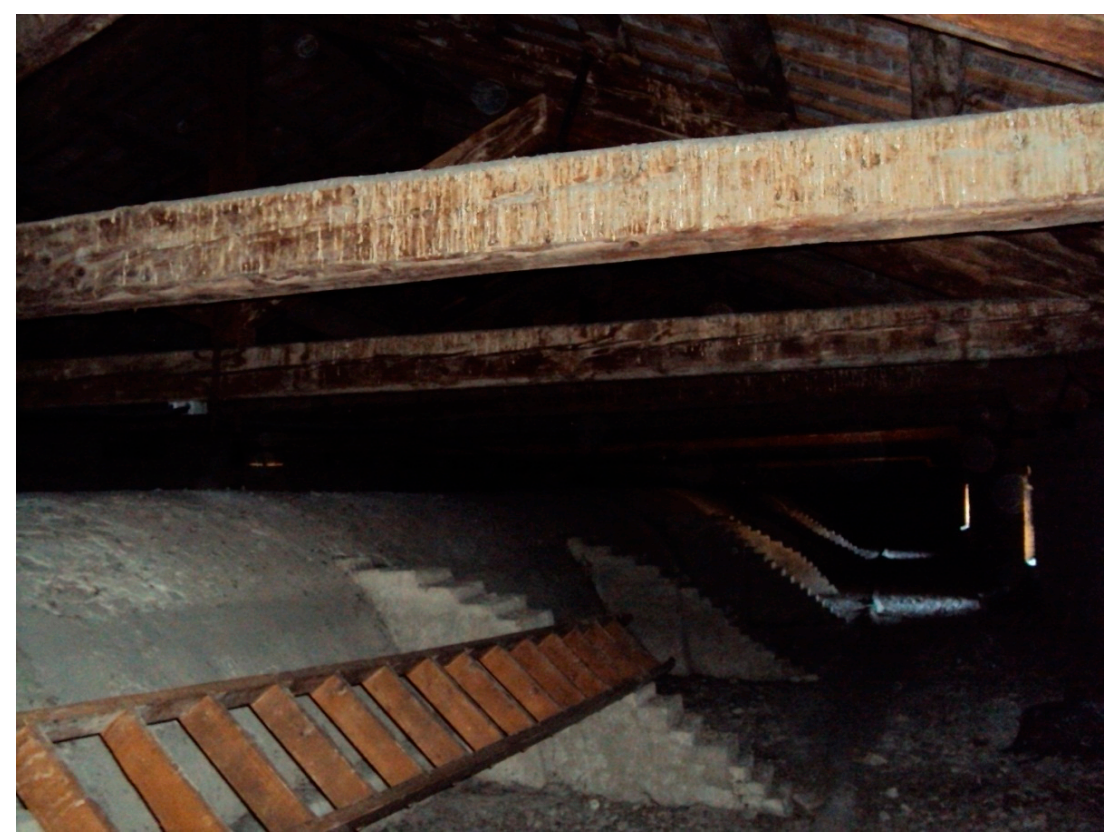

Figure 5. The attic on the top of the Library.

The indoor section of the library is separated from direct contact:

(a) from the ground level and other rooms (the space occupied by the archaeological museum is not air conditioned) and so it is isolated from thermal exchanges; and

(b) from incident solar radiation, direct or diffused on the attic floor, because it is not involved in these energetic exchanges due to the air volume of the attic (also, in this case, there are not any HVAC plants) and the air has the same outdoor temperature.

The attic, over the library, has the same geometry and structure with brick wall. The total surface is $427 \mathrm{~m}^{2}$, with three windows, of $0.48 \mathrm{~m}^{2}$, without frame, for each longitudinal side. The roof structure is a wooden truss, with wood splines and brick tiles. The roof does not have any insulation. The ridge is $15.60 \mathrm{~m}$ above the ground floor. The attic's volume is $1386 \mathrm{~m}^{3}$.

The space under the library houses the Archaeological Museum, where the San Francesco Convent refectory once stood. It has the same geometry as the library (obvious) with a volume of $2142 \mathrm{~m}^{3}$. The structure is a brick wall, column, and barrel vault. The ground floor has two naïves with a cross vault, a central nave, and two lateral aisles with a cross vault of the upper Malatestiana Library. The ground floor has seven windows on one sidewall and six on the other, with wooden frames and glass. The access door is wooden, and all windows have wrought-iron gratings.

The indoor library volume is protected from the effects produced by the horizontal component of solar radiation; so, only the vertical walls are exposed to the east, the south and the west according to the solar diagram. The area occupied by the vertical walls is less than that occupied by the horizontal elements of the roofing and flooring. Therefore, the effects of direct solar irradiation on the vertical walls and the incidental heat transmission from outside to inside are reduced. In any case, the heat flow by solar irradiation depends on wall thermal displacement due to the thermo-physics and thermal capacity of the walls. The manuscripts conserved in the library are monitored and controlled and subject to periodic assessment, and if necessary, conservation. The manuscripts, reproduced and available in digital format, can be consulted in exceptional cases by historians; in such cases, the requested manuscript is removed from the library by the librarian and consulted in another part 
of the library. The Malatestiana Library was the object of indoor microclimate monitoring during 2013 research; the results were published in Fabbri [23].

\section{The Scenarios}

As mentioned earlier, the Malatestiana Library was modeled by means of IESVE; the input data concern geometry, the thermo-physics parameter, window opening, and climate data. The output data of the simulation are:

- indoor air temperature $\left({ }^{\circ} \mathrm{C}\right)$;

- $\quad$ indoor relative humidity $(\%)$;

- $\quad$ air velocity $(\mathrm{m} / \mathrm{s})$;

- $\quad$ occupant Predicted Mean Vote (PMV).

The aims of the study are to evaluate the natural ventilation incidence with different kinds of window opening times. The building energy performance simulation interests the entire building, ground floor, library, and attic, but the results are only for the library. The scenarios carried out are the following:

(1) with all 44 windows closed, for all days during the year;

(2) with six windows open $2 \mathrm{~h}$ per day. In this case, we consider three windows opened for each side, from 7 a.m. to 9 a.m. The library caretaker confirmed that these are "as usual" scenarios. In this case, we have new air ventilation from outdoor climate data;

(3) with six windows open $12 \mathrm{~h}$ per day. In this case, the building simulation considers three windows open from 7 a.m. to 7 p.m. In this case, the outdoor climate has a greater incidence on the indoor air.

We do not consider other kinds of window opening scenarios, because the above cases include the majority of cases, e.g., the caretaker advised us that all 44 windows are never opened, and windows are never open all day, not even in summer.

The second typology of scenario concerns a building section configuration, in other words, we would like to know the ground floor's and the attic's influence on the library's indoor microclimate. The three scenarios are:

(a) the actual building, with six windows open $2 \mathrm{~h}$ per day;

(b) the building without the attic, with six windows open $2 \mathrm{~h}$ per day, in order to evaluate solar irradiation's influence;

(c) the building without the ground floor, with six windows open $2 \mathrm{~h}$ per day, to evaluate the basement terrain's influence.

\section{Results and Discussion}

The results of the BPSs show different indoor air behaviors based on the boundary conditions. We will report each case with comments.

In Case 1 , the simulation shows that the average indoor air temperature is $17.77^{\circ} \mathrm{C}$, whereas the $\mathrm{RH}$ is $45.37 \%$; furthermore, during the period March-July, the average air temperature is $20.91{ }^{\circ} \mathrm{C}$ and the RH is $55.60 \%$. Following Italian Law, by Italian Ministry of Cultural Heritage and Tourism (MIBAC) (MIBAC, 1998, “Atto di indirizzo" Dlgs 112/1998 art.150 comma 6, pg.144), the standard range values in the case of manuscripts define the range values of temperature and $\mathrm{RH}$, of an indoor air microclimate, as between 13 and $18{ }^{\circ} \mathrm{C}$ (to an extent to $20^{\circ} \mathrm{C}$ ) and an $\mathrm{RH}$ of between 55 and $66 \%$. The IESVE simulation shows that the indoor air of the Library is above the standard range values. The peak temperature, during summer time, is $27^{\circ} \mathrm{C}$, and the temperature is over $25^{\circ} \mathrm{C}$ only for one week in a year. 
The CFD analysis needs only to simulate a specific day and schedule. We decided to simulate on the hottest day, which is defined by IESVE as 8 July at 12:00 p.m. The result of the simulation is that the temperature is homogeneous inside the library, with an average value of $21^{\circ} \mathrm{C}$. The air velocity is zero $\mathrm{m} / \mathrm{s}$, because the windows are closed all day.

In Case 2, the simulation shows that the average indoor air temperature is $17.05^{\circ} \mathrm{C}$, only $-0.72{ }^{\circ} \mathrm{C}$ less than Case 1, and the RH value is $69.26 \%, 13.66 \%$ more than Case 1 . This is because the indoor air has a natural ventilation with the outdoor air, that has more moisture, especially in winter and on rainy days, than the inside air. The IESVE simulation shows a longer duration, compared to Case 1 , in a period when the air temperature and $\mathrm{RH}$ are within the standard range values defined by MICAB. The peak temperature during summer time is $27^{\circ} \mathrm{C}$, and the temperature is over $25^{\circ} \mathrm{C}$ only for one week in July. The RH value changes every day and all year, but the air is never very dry (RH lower than $40 \%)$.

The CFD analysis shows a peak indoor air velocity on 15 October at 7:00 a.m. The indoor air temperature is $16^{\circ} \mathrm{C}$ and the air velocity increases near the windows (Figure 6).

In Case 3, the simulation shows that the average indoor air temperature is $18.12{ }^{\circ} \mathrm{C}$, only $+0.35^{\circ} \mathrm{C}$ less than Case 1, but more than $+1{ }^{\circ} \mathrm{C}$ higher than Case 2 . The $\mathrm{RH}$ average value is $70.33 \%$, nearly the same $\mathrm{RH}$ as in Case 2 , but more than $+14.73 \%$ in relation to Case 1 , the driest case. Window opening and indoor/outdoor air natural ventilation should be a problem in order to guarantee indoor air standard range values following the MIBAC law. These results show how window opening and maintenance care, by the library caretaker, have a positive influence on manuscript and artifact conservation. The CFD analysis shows a peak indoor air velocity on 2 December at 7:00 a.m.

The IESVE simulation shows a longer duration, compared to Case 1, the same as Case 2, in a period when air temperature and $\mathrm{RH}$ are within the standard range values defined by MICAB. The peak temperature during summer time is $27^{\circ} \mathrm{C}$, and the temperature is over $25^{\circ} \mathrm{C}$ only for one week in July.

The $\mathrm{RH}$ values change during the day and during the year; furthermore, there are more cases presenting an $\mathrm{RH}$ greater than 70\% compared to Case 2. The CFD simulation (Figure 7) shows an average temperature of $15^{\circ} \mathrm{C}$, and air velocity increases near windows and in the middle of the center nave of the library.

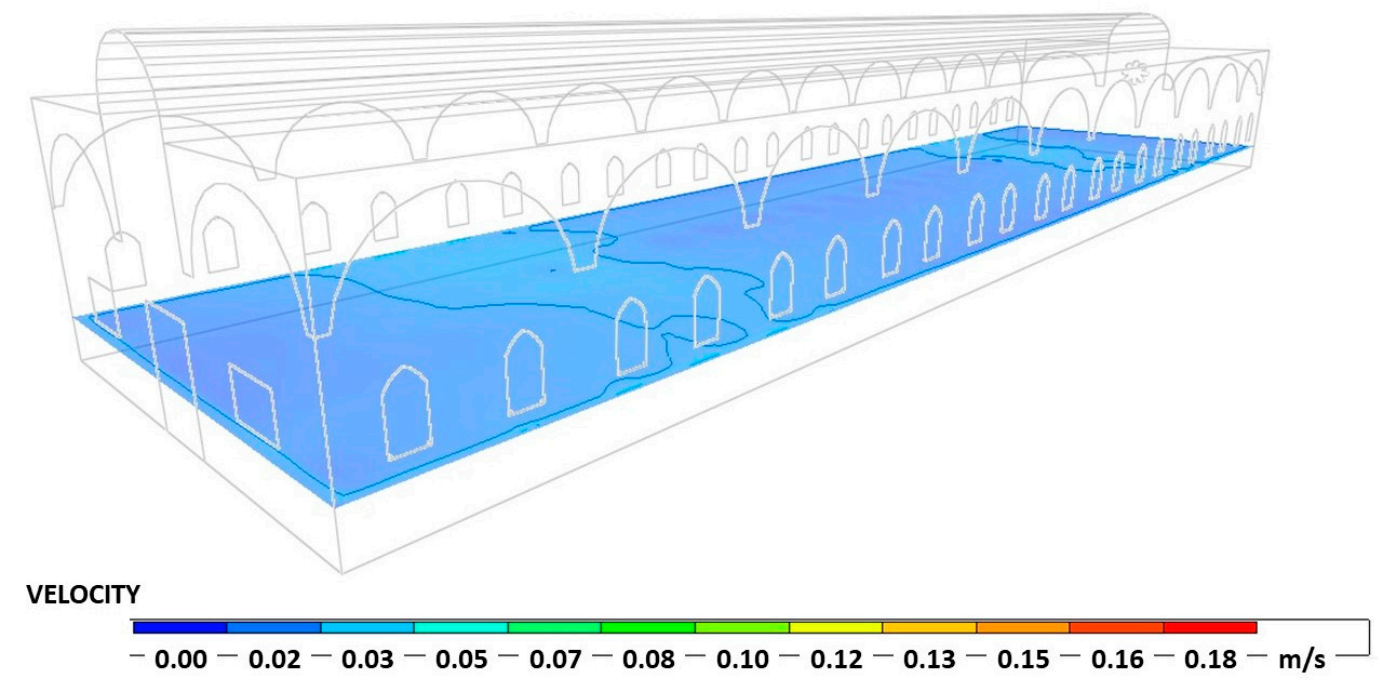

Figure 6. Indoor air velocity in the middle of central nave. 


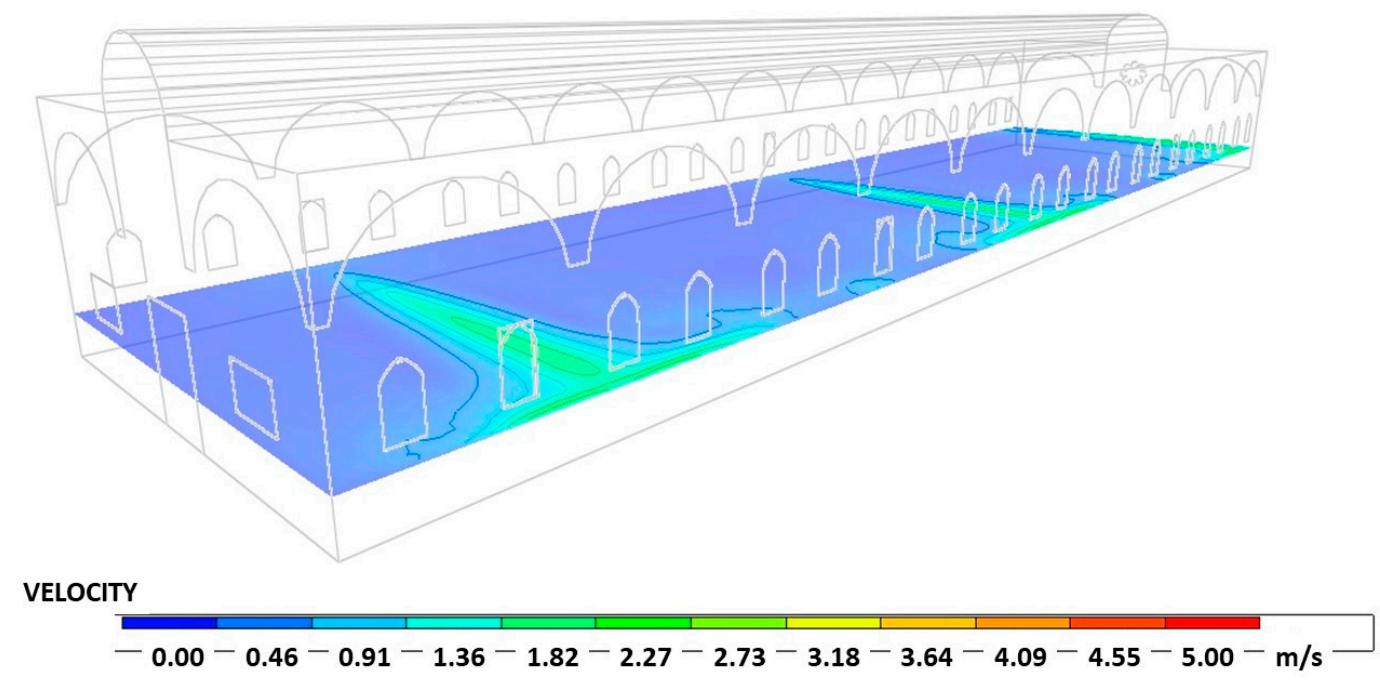

Figure 7. Indoor air velocity in the middle near the windows.

The second part of the study regards the architectural form of the building:

(a) the actual architectural section, compared with:

(b) without the attic, and

(c) without the ground floor museum.

Figure 8 shows a conceptual scheme of the three simulations.

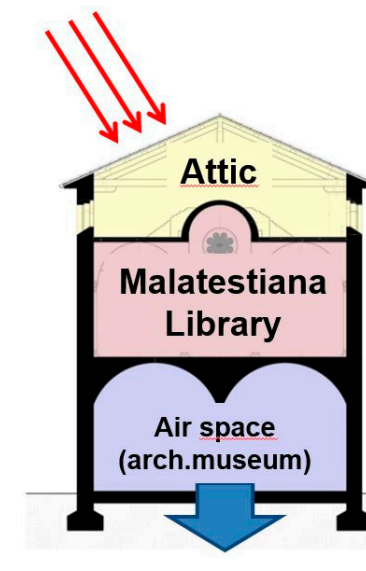

a)

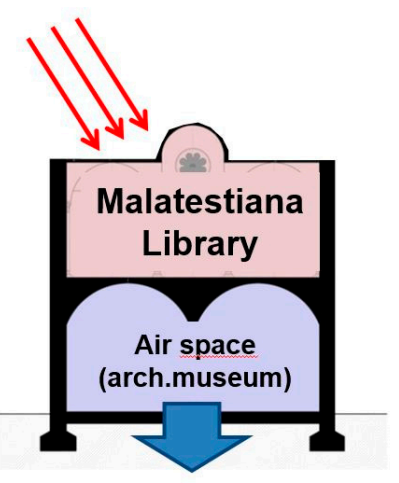

b)

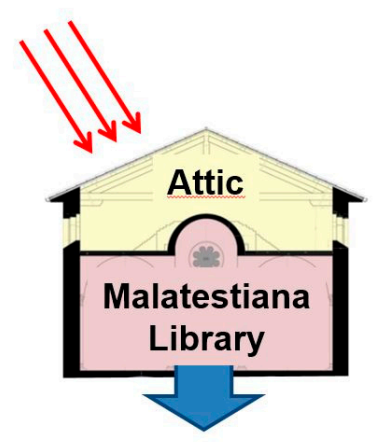

c)

Figure 8. Conceptual scheme of the further simulations. (a) actual architectural section; (b) simulation without roof; (c) simulation without air space of the ground floor.

These simulations consider windows opening $2 \mathrm{~h}$ per day, which represent the actual use and maintenance of the buildings. We consider the case (a), the building with the original architectural section, as our baseline (Case 2).

In Figure 8b, solar radiation is directly on the library's roof, so the indoor air has an increase of solar energy. The results of the IESVE simulation show a longer duration of standard range values of air temperature and $\mathrm{RH}$. The peak temperature, during summer time, is nearly $27^{\circ} \mathrm{C}$, but the temperature is over $25^{\circ} \mathrm{C}$ only for all of the summer season. In this case, the average annual temperature is $14.13^{\circ} \mathrm{C}$, with a gap of $-2.92{ }^{\circ} \mathrm{C}$, and an annual RH of $39.89 \%$, with a gap of nearly $40 \%$ in spite of case (a). In this case, the indoor air should be drier than a building with an attic. 
We can suppose that a configuration without the attic could have a higher temperature during summer, and consequently a lower RH value. These facts should cause a modification of the indoor air's condition with damage to the manuscripts' elasticity and hygroscopicity.

The result of the IESVE simulation of the air temperature (Figure 9) shows an irregular air temperature distribution inside the environment compared to baseline trends. The CFD simulation of air velocity (Figure 10) shows an increase of air velocity $(0.15 \mathrm{~m} / \mathrm{s})$ in the middle of the building that probably depends on convective and air stratification at the upper side of the central nave. In Figure 8c, the library's basement is in direct contact with the ground.

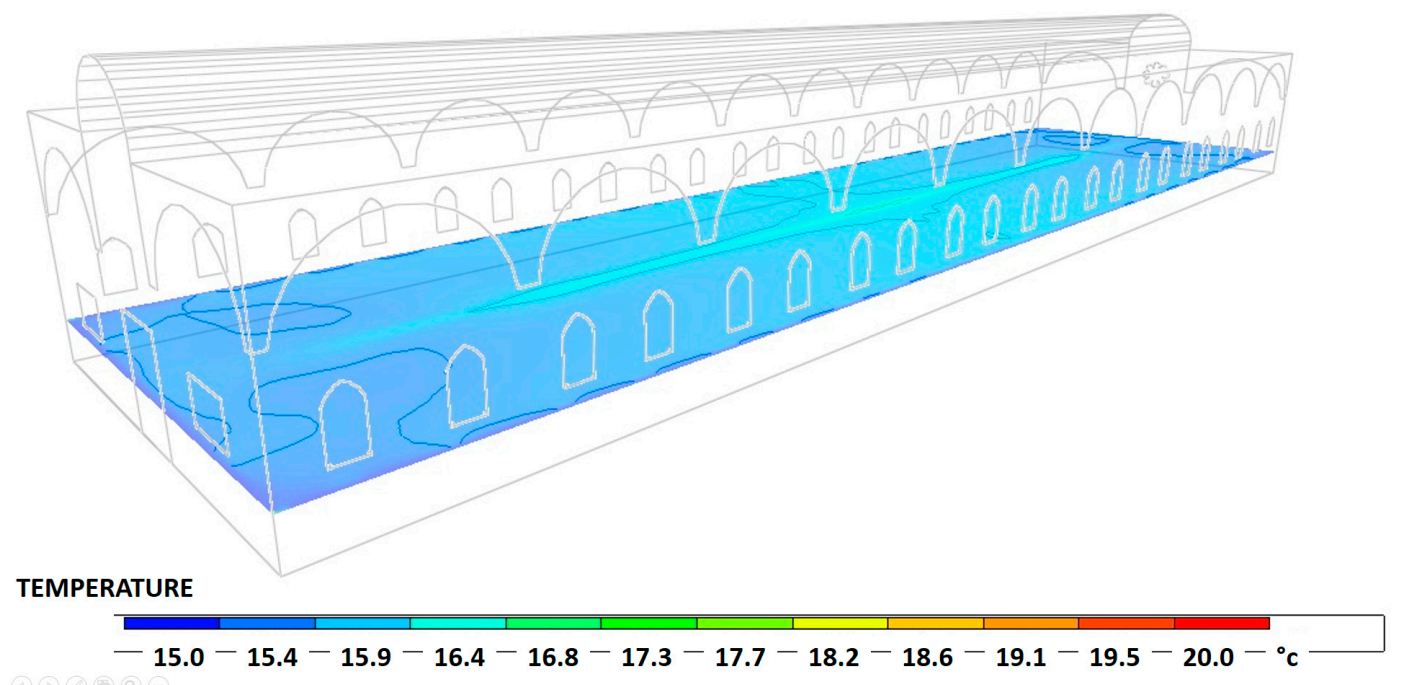

Figure 9. Distribution maps of the temperature.

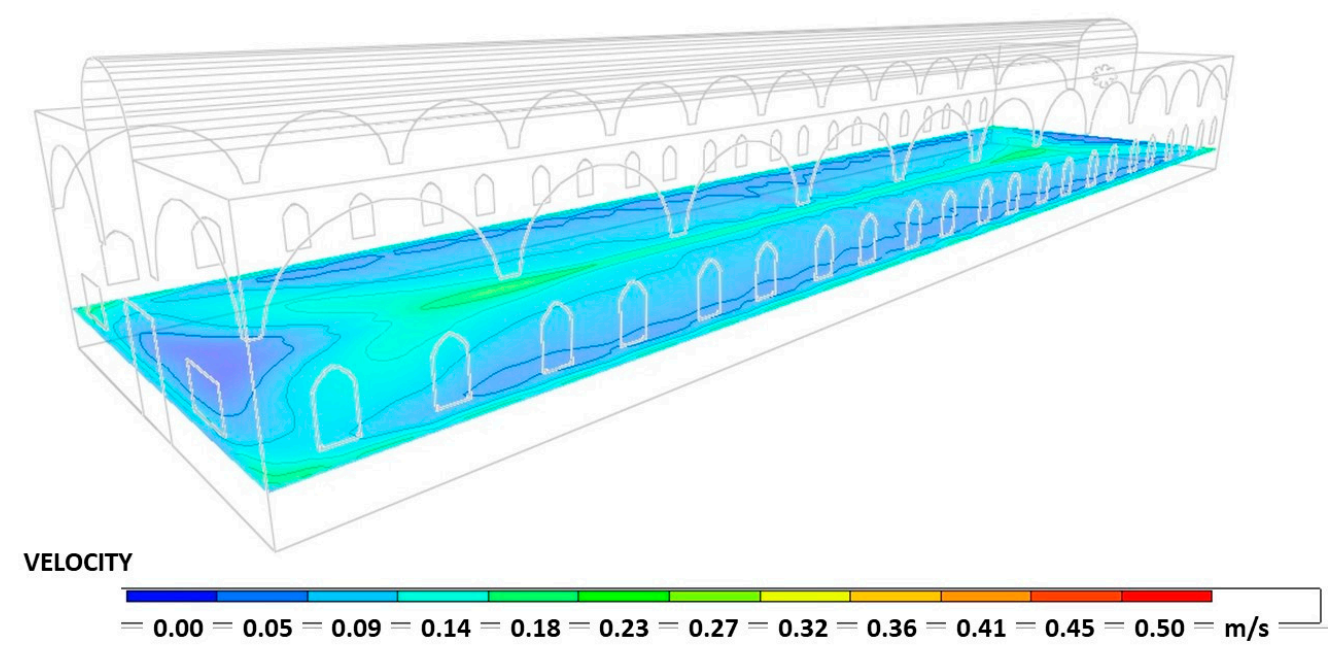

Figure 10. Distribution maps of air velocity.

The IESVE simulation results show a shorter period of standard range values, by the MIBAC law; moreover, there is an increase in the daily gap difference of indoor air temperature and $\mathrm{RH}$, increasing the damaging effect on the artifacts and manuscripts. In this case, compared with the case (b) without the attic configuration, the results do not show a peak temperature, but the temperature trends are lower than the case (a), actual architectural section. The annual average temperature is $13.37^{\circ} \mathrm{C}$, with a gap of $-3.68{ }^{\circ} \mathrm{C}$, but the average $\mathrm{RH}$ value is $70.16 \%$, with a gap of nearly $1.5 \%$ in spite of case (a), slightly higher than baseline. In the building without a museum, the average temperature 
is nearly the same as the baseline, but the RH increases, and depends on the effect of the basement which is in direct contact with the ground.

In the building without the attic, unlike in a complete building, the annual average temperature increases, depending only on direct solar radiation on the library's roof top.

These results show the importance of BPS applied to heritage buildings, so if we can consider that it is obvious that detaching the library from the basement would reduce water infiltrations from the ground, on the contrary, such a large attic has been chosen to reduce the high summer temperatures which damage the artifacts that are stored inside the building.

\section{Conclusions}

A BPS allows us to verify indoor microclimate parameters based on different window and architectural configurations. Each case study scenario presents a gap compared with a real building. These depend on:

(a) building geometry: in the Google Sketchup software model, we decided to use a simplified model of indoor volume, so we removed an indoor column and a wooden desk, which could play a role in CFD and air velocity, especially to study dust distribution. Furthermore, historical buildings are more difficult to analyze as they have more details and different shapes compared to residential buildings;

(b) we did not consider the outdoor context—-the neighboring buildings—-because they are far from the Malatestiana Library and so have no influence on the radiation or other outdoor data; maybe only the outdoor pavement, in particular the courtyard lawn grass, could have a small influence on the outside temperature.

In this sense, future studies applying Building Performance Software should be improved with geo-location outdoor climate data from a global positioning system (GPS). We would like to improve our studies with GAIAG [24], a Satellite Application Facility for Decision-Making. The company works in remote sensing for the Global Monitoring Environment and Security (GMES) application integrated with the OGC standard (Open Geospatial Consortium standard) in compliance with the INSPIRE European Directive for the management of spatial data. The integration of satellite data would allow us to obtain data input in file extension WEA, EPW, or CSV code with real geo-related data, with satellite monitoring data. The different kinds of acquirable data allow for the improvement of quality and efficiency in Building Energy Performance models.

Furthermore, the BEP software:

(i) analyzes indoor $\mathrm{CO}_{2}$ (carbon dioxide) distribution produced by visitors. We decided to not do this simulation because the measurements show still air and library visits are strictly regulated, only a maximum of 20 persons, for 15-20 min, with a maximum of 80-100 visitors per day, with a peak of 3000 visitors/day. Furthermore, visitors can visit only the first $3 \mathrm{~m}$ of the entrance area;

(ii) adopts the HVAC design (or validation), or simulates a HVAC system's effect (or damage) on the Malatestiana Library. We would like to highlight a fact: HVAC systems are not present because they can modify the indoor microclimate and damage artifacts, manuscripts, and the actual building;

(iii) evaluates the predicted mean vote (PMV) and predicted percentage of dissatisfied (PPD) of thermal comfort also with a CFD simulation. An interesting study concerns the simulation of the PMV and PPD at the original Malatestiana Library during the XV-XIX century, when the neutral value of the PMV was under a $-1.5 \approx-2$ value.

The main difficulty in BPS is to insert all data, which is however simplified by the IESVE interface and Google Sketchup. An advantage is the accuracy of modeling, which allows for the simulation of several conditions, as this present paper demonstrates. The BPS could be adopted to verify a building design or existing building, but another clever use is to use this software as a design tool, in the 
case of new or retrofit buildings, or an investigation tool in the case of heritage buildings. In this research, we do not use the IESVE software with aims to verify; instead, we would like to investigate the architectural sections of buildings and the influence of maintenance on indoor air.

A BPS should be implemented in historical and archaeological investigations, e.g., PMV simulation to discover the ancient habits used in the library or perhaps even the type of clothes they wore to read in such buildings.

In our research, the BPS has been done following an indoor monitoring campaign, in order to measure the effect on:

(1) building and windows opening management; and

(2) building attic and ground floor influence on the indoor microclimate of the Malatestiana Library.

The result allows us to understand the indoor environmental role of the architectural section, in order to know if the designer has a role in choosing an environmental control strategy. Following an archaeological study analysis criterion, we observed that several libraries built in the same century have the same architectural sections, e.g., the San Marco Library in Florence (XV century), the Santa Maria Incoronata Library in Milan (XV century), and the Monte Oliveto Library in Asciano, Tuscany (XV century), all have the same architectural section design. These libraries, however, have been modified over time.

The BPS confirms to us that the architectural Renaissance design criterion (proportion, symmetry, golden section, etc.) are not just an "aesthetic criterion", but they could be compared-with an empirical approach-to a current BPS model in order to discover indoor air environmental behavior.

In our opinion, this is the most relevant discovery of this research, because BPSs show a direct and close relation between aesthetics and the environment, and between library architecture and an "ante-literam" environmental design. In conclusion, the BPE model should also be used as an archaeological/architectural tool to discover the environmental design strategies of the past.

Acknowledgments: The authors wish to acknowledge Giulia Angeli for her support during the research. Furthermore, the authors would like to thank the caretakers and the Deputy Director, Paola Errani, who granted access to the Library, and for their kindness, attention, and care shown in the management and conservation of the Malatestiana Library.

Author Contributions: The study was designed by Lamberto Tronchin and Kristian Fabbri. Kristian Fabbri performed measurements by means of equipment belonging to Lamberto Tronchin. The simulation, the results, and the analysis were performed, analysed, and checked by Kristian Fabbri and Lamberto Tronchin. All authors have read and approved the final manuscript.

Conflicts of Interest: The authors declare no conflict of interest.

\section{References}

1. Ascione, F.; de Rossi, F.; Vanoli, G.P. Energy retrofit of historical buildings: Theoretical and experimental investigations for the modelling of reliable performance scenarios. Energy Build. 2011, 43, 1925-1936. [CrossRef]

2. Balocco, C.; Grazzini, G. Plant refurbishment in historical buildings turned into museum. Energy Build. 2007, 39, 693-701. [CrossRef]

3. D'Agostino, D.; Congedo, P.M. CFD modeling and moisture dynamics implications of ventilation scenarios in historical buildings. Build. Environ. 2014, 79, 181-193. [CrossRef]

4. Corgnati, S.P.; Perino, M. CFD application to optimise the ventilation strategy of Senate Room at Palazzo Madama in Turin (Italy). J. Cult. Heritage 2013, 14, 62-69. [CrossRef]

5. D'Agostino, D. Moisture dynamics in an historical masonry structure: The Cathedral of Lecce (South Italy). Build. Environ. 2013, 63, 122-133. [CrossRef]

6. D'Agostino, D.; Congedo, P.M.; Cataldo, R. Ventilation Control using Computational Fluid-dynamics (CFD) Modelling for Cultural Buildings Conservation. Procedia Chem. 2013, 8, 83-91. [CrossRef]

7. Bernardi, A.; Todorov, V.; Hiristova, J. Microclimatic analysis in St. Stephen's church, Nessebar, Bulgaria, after the invention for the conservation of frescoes. J. Cult. Heritage 2000, 1, 281-286. [CrossRef] 
8. Samek, L.; De Maeyer-Worobiec, A.; Spolnik, Z.; Bencs, L.; Kontozova, V.; Bratasz, L.; Kozlowski, R.; Van Grieken, R. The impact of electric overhead radiant heating on the indoor environment of historic churches. J. Cult. Heritage 2007, 8, 361-369. [CrossRef]

9. Tronchin, L.; Fabbri, K. Analysis of buildings' energy consumption by means of exergy method. Int. J. Exergy 2008, 5, 605-625. [CrossRef]

10. Tronchin, L.; Manfren, M.; Tagliabue, L.C. Optimization of building energy performance by means of multi-scale analysis-Lessons learned from case studies. Sustain. Cities Soc. 2016, 27, 296-306. [CrossRef]

11. Camuffo, D.; Bernardi, A.; Sturaro, G.; Valentino, A. The microclimate inside the Pollaiolo and Botticelli rooms in the Uffizi gallery, Florence. J. Cult. Heritage 2002, 3, 155-161. [CrossRef]

12. Litti, G.; Audenaert, A.; Braet, J.; Lauriks, L. Energy environmental monitoring in historical buildings: A simplified methodology for modelling realistic retrofitting scenarios: The case study of Schoonselhof Kasteel in Antwerp (Belgium). In Built Heritage 2013 Monitoring Conservation Management; Politecnico di Milano (Milan Polytechnic): Milan, Italy, 2013; pp. 1075-1083.

13. Litti, G.; Audenaert, A.; Braet, J. Energy retrofitting in architectural heritage, possible risks due to the missing of a specific legislative and methodological protocol. In Proceedings of the 2013 European Conference on Sustainability, Energy and Environment, Brighton, UK, 4-7 July 2013; pp. 127-137.

14. La Gennusa, M.; Rizzo, G.; Scaccianoce, G.; Nicoletti, F. Control of indoor environments in heritage buildings: Experimental measurements in an old Italian museum and proposal of a methodology. J. Cult. Heritage 2005, 6, 147-155. [CrossRef]

15. Camuffo, D.; Brimblecombe, P.; Van Grieken, R.; Busse, H.; Sturaro, G.; Valentino, A. Indoor air quality at the Corrier museum, Venice, Italy. Sci. Total Environ. 1999, 236, 135-152. [CrossRef]

16. Tronchin, L.; Fabbri, K. Energy Performance Certificate of building and confidence interval in assessment: An Italian case study. Energy Policy 2012, 48, 176-184. [CrossRef]

17. IES.VE. Integrate Environmental Solution-Virtual Environment. Available online: www.iesve.com (accessed on 12 October 2017).

18. Said, M.N.A.; Brown, W.C.; Shirtliffe, C.J.; Maurenbrecher, A.H.P. Monitoring of the building envelope of a heritage house: A case study. Energy Build. 1999, 30, 211-219. [CrossRef]

19. Ellis, P.; Torcellini, P.; Crawley, B. Energy Design Plugin: An EnergyPlus Plugin for SketchUp. In Proceedings of the IBPSA-US SimBuild 2008 Conference, Berkeley, CA, USA, 30 July-1 August 2008.

20. Attia, S.; Hensen, J.L.M.; Beltràn, L.; De herde, A. Selection criteria for building performance simulation tools: Contrasting architects' and engineers' needs. J. Build. Perform. Simul. 2012, 5, 155-169. [CrossRef]

21. UNESCO 2005a Memory of the World-The Malatesta Novello Library. Available online: http:/ /www.unesco. $\mathrm{org} /$ new / en/communication-and-information/flagship-project-activities / memory-of-the-world/register/ full-list-of-registered-heritage/registered-heritage-page-8/the-malatesta-novello-library/ (accessed on 12 October 2017).

22. Fabbri, K.; Tronchin, L.; Tarabusi, V. Real Estate market, energy rating and cost. Reflections about an Italian case study. Procedia Eng. 2011, 21, 303-310. [CrossRef]

23. Fabbri, K.; Pretelli, M. Heritage buildings and historic microclimate without HVAC technology: Malatestiana Library in Cesena, Italy, UNESCO Memory of the World. Energy Build. 2014, 76, 15-31. [CrossRef]

24. Gaiag. Satellite Application Facility for Decision Making. Available online: www.gaiagsat.eu (accessed on 12 October 2017).

(c) 2017 by the authors. Licensee MDPI, Basel, Switzerland. This article is an open access article distributed under the terms and conditions of the Creative Commons Attribution (CC BY) license (http:/ / creativecommons.org/licenses/by/4.0/). 